\title{
THE EXPERIENCE IN PEDIATRIC PATIENTS WITH EATING DISORDER FOR 10 YEARS
}

\section{LA EXPERIENCIA EN PACIENTES PEDIÁTRICOS CON DESÓRDENES ALIMENTICIOS DURANTE 10 AÑOS}

\author{
Ramírez-Sánchez, Fátima"; Jaimez-Pérez, Sonia'; Gil-Campos, Mercedes²,; Flores-Rojas, \\ Katherine ${ }^{1}$
}

1 Pediatric metabolic and research Unit, Reina Sofia University of Córdoba. Maimónides Biomedical

Research Institute of Córdoba (IMIBIC). University of Córdoba.

${ }^{2}$ Spanish Biomedical Research Centre in Physiopathology of Obesity and Nutrition (CIBERobn), Instituto de Salud Carlos III (ISCIII), Madrid.

Recibido: 29/07/2020 | Revisado: 08/08/2020 | Aceptado: 03/10/2020

DOI: 10.15568/am.2020.811.or05

Actual Med. 2020; 105(811): 182-189

\section{Original}

\section{RESUMEN}

Objetivos: Existe un llamativo aumento de los trastornos de la conducta alimentaria en pacientes pediátricos en los últimos años. Identificar determinados perfiles clínicos puede mejorar el conocimiento relacionado con factores de predisposición o desencadenantes, y el pronóstico de estos trastornos en este rango de edad. Por tanto, el objetivo principal de este estudio es describir el perfil de un grupo de pacientes pediátricos con trastornos de la conducta alimentaria con el fin de mejorar el enfoque de los pediatras a dichos trastornos de inicio temprano y promover intervenciones protocolizadas como una herramienta esencial para mejorar la salud de estos niños. Métodos: Se presenta un estudio retrospectivo de los pacientes pediátricos diagnosticados con trastornos alimentarios desde 2009 hasta 2019 en un hospital pediátrico de tercer nivel tras valorar características demográficas, biográficas, antropométricas, psiquiátricas y clínicas, así como otras relacionadas con el diagnóstico y tratamiento.

Resultados: Los síntomas de los niños son similares a los de adultos y adolescentes, pero se presentan más frecuentemente como formas incompletas de la enfermedad. Las principales diferencias incluyen una proporción por sexos más equitativa, un menor tiempo de evolución de la enfermedad antes del diagnóstico, un menor deterioro del estado de salud en la primera evaluación y una menor duración de la enfermedad.

Conclusiones: El mejor pronóstico en los niños podría explicarse por el seguimiento médico más estrecho de estos pacientes y la mejor adherencia al tratamiento, la intervención temprana de los padres y la mayor dependencia hacia sus cuidadores en la elección de alimentos y la ingesta, así como mayor plasticidad para el tratamiento psicológico y la coordinación del equipo multidisciplinar en el proceso asistencial.

\section{ABSTRACT}

Aim: In recent years, there has been a remarkable increase in eating disorders among pediatric patients. The identification of certain clinical profiles allows us to better understand predisposing or triggering factors, as well as disorder prognosis in this age range. Therefore, the main objective of this study is to describe the patterns of pediatric patients with eating disorders to improve the approach of Pediatricians for these early-onset disorders and promote protocolized interventions as an essential tool to improve the health of these children.

Methods: A retrospective study of pediatric patients diagnosed with eating disorders from 2009 to 2019 in a third-level pediatric hospital evaluated the demographic, biographical, anthropometric, psychiatric, and clinical characteristics, as well as others related to diagnosis and treatment

Results: Symptoms among children are similar to those experienced by adults and adolescents; however, incomplete forms of the disease are more frequent in children. The main differences between the age groups include a more equitable sex ratio, a shorter time evolution of the disease before diagnosis, less deterioration of overall health state in the first evaluation and a shorter duration of the disorder.

Conclusions: The best prognosis in children could be explained by the closer medical follow-up of these patients and their better adherence to treatment, the early intervention of parents and higher dependence on their caregivers in food choices and intake. In addition, greater plasticity for psychological treatment and coordination of the multidisciplinary team in the care process also contributed the observed trend.

Correspondencia

Mercedes Gil-Campos

Reína Sofia University Hospital

Avda. Menéndez Pidal, sn · 14004, Córdoba, Spain.

E-mail: mercedes_gil_campos@yahoo.es
Palabras Clave: Trastornos de la Conducta alimentaria Anorexia nerviosa: Bulimia nerviosa; Infancia

Keywords: Eating disorders: Anorexia nervosa; Bulimia nervosa: Children. 


\section{INTRODUCTION}

Over the last few years there has been a notorious increase in eating disorders (EDs) incidence among pediatric patients, becoming the most frequent chronic juvenile diseases. Currently, the diagnosis of EDs is based on criteria of the American Academy of Psychiatry, DSM-V (1), or the criteria selected by the World Health Organization in CIE-10(2), for the pediatric population too. EDs include: anorexia nervosa $(\mathrm{AN})$, bulimia nervosa $(\mathrm{BN})$, restrictive avoidance disorder of food intake (ARFID), binge ED, unspecified ED (EDNOS), itching and rumination disorders (2).

These are psychiatric conditions consistent with abnormal eating habits, a well-defined alteration of the intake pattern or a behavioral alteration related to weight control, which cannot be explained by other organic or psychiatric causes.

The greatest difficulty in diagnosis is related to the clinical variability, due especially to the atypical onset and the incomplete clinical forms of these disorders. The clinical manifestations of patients with EDs are multisystemic and may fluctuate according to the stage of the disorder. Besides, the classical profile of these patients is quickly evolving; now there are higher rates of EDs in younger children, male patients, and minority groups (3).

One of the main problems is that pediatricians and family doctors are often not specialized in these pathologies, which could result in a delayed diagnosis.

In addition, certain complications derived from the disease might turn out to be fatal, meaning all spheres of the patient's life must be carefully explored through an optimal psychiatric, medical and nutritional evaluation (3-5). In fact, a higher prevalence of morbidity with malnutrition, leading to physical and psychosocial impairment has been associated.

Brain functions are affected profoundly, resulting in eating disorders having the highest risk of suicide and mortality rate of all of the juvenile psychiatric conditions (6-8).

Commonly, the findings of late adolescents and adults in the spheres of evaluation, clinical signs, and treatments are often extrapolated to pediatric patients. This should be carefully considered since children may have a particular profile with important differences. So, the main goal of this study is to describe the patterns of pediatric patients with EDs to improve the approach of Pediatricians for early-onset EDs and promote protocolized interventions as an essential tool to improve the health of these children.

\section{MATERIALS AND METHODS}

A retrospective, observational and descriptive study was performed on patients with EDs in the Metabolism Unit of a third-level Pediatric Hospital for 10 consecutive years (2010-2019, both included) after the application of an integrated assistance process protocolized by the government (Junta de Andalucía, Spain) based on a multidisciplinary and specialized professionals assistance (9). Children included in the assistance process were those under 14 years of age (In Spain, the pediatric age is considered up to 14 years) with severe restrictive EDs, who had been derived to the Metabolism Unit from the Children's Mental Health Unit of the Hospital due to their severity or because of their complexity. The diagnosis of EDs and the type (AN, BN, etc.) was made according to DSM-V criteria. The main exclusion criteria were children with behavioral disorders that finally were not classified as EDs.

Anamnesis and physical examination, including the evaluation of sexual maturity and blood pressure were assessed at baseline and in regular visits. Weight and height were measured using standardized procedures. Body mass index (BMI) and Z-scores for anthropometric measures were calculated using the standard growth percentile tables for the Spanish population (10). Electric bioimpedance analysis (BIA) multifrequencial four-phase was carried out with a Tanita $\mathrm{BC}-418^{\circ}$. Before this evaluation, children were instructed to urinate prior to the evaluation; do not perform moderate or intense physical activity $24 \mathrm{hr}$ before and an overnight fast $>12 \mathrm{~h}$. This device classifies the percentage of body fat as low fat, healthy, high fat and obese, according to healthy levels for sex, age and body stretch. Standard food frequency intake and 24-hour diet recall method questionnaires were made to collect information on food habits. Blood analysis tests were conducted at the laboratory of the hospital using the Architect i2000SR and c16000 automatic analyzer, Abbott Diagnostics w, Abbott Laboratories, according to the manufacturer's specifications.

The psychological study of patients and the detection of the psychiatric comorbidities associated with the disease was conducted in the Children's Mental Health Unit of the Hospital by a multidisciplinar group.

The statistical analysis based on a descriptive analysis with measures of central tendency of quantitative variables expressed as means $(\mathrm{m})$ or median, mode and range, and standard deviations (SD). Qualitative variables were expressed as counts (n) and proportions (\%). The data obtained were processed with the SPSS Statistics version 22.

This study was approved by the Hospital's Institutional Ethics committee, following the guidelines established in the Declaration of Helsinki, with anonymity and special protection of data per the law. 


\section{RESULTS}

20 children with EDs were selected for this study. The sex ratio was $3: 1 ; 75 \%$ of the patients were women and $25 \%$ men. $70 \%$ of patients had AN (93\% in girls). Of them, $25 \%$ evolved to $\mathrm{BN}$. The clinical data related to the debut of EDs and the first visit, are described in table 1 .
The age of onset was earlier in boys than in girls; however, the mean time of illness before the first consultation was shorter in girls. $43 \%$ had a lower weight than P10 at the first visit. The median weight loss before the first evaluation was $11 \mathrm{~kg}$, although they maintained the same amount of lean mass. In BIA, most of the patients were in normal-low ranges in fat and lean mass, for its references (\% in table 1).

\begin{tabular}{|c|c|c|c|}
\hline Characteristics & Mean \pm SD & Median & Mode \\
\hline Age of ED onset (years) & $11.3 \pm 2.4$ & 12 & 13 \\
\hline Age of ED onset in AN (years) & $11.3 \pm 2.3$ & 12 & 12 \\
\hline Age of ED onset in BN (years) & $12.2 \pm 1.5$ & 13 & 13 \\
\hline Age of ED onset Girls (years) & $11.7 \pm 2.2$ & 12 & 13 \\
\hline Age of ED onset Boys (years) & $10 \pm 2.7$ & 10 & $6 *$ \\
\hline Age of first consultation (years) & $11.8 \pm 2.0$ & 12 & 13 \\
\hline Girls (months) & $2.4 \pm 6.7$ & 12 & 0 \\
\hline Boys (months) & $19.2 \pm 21.7$ & 12 & 0 \\
\hline Weight (kg) & $39.8 \pm 14.8$ & 38 & 52.2 \\
\hline Weight percentile & $35.0 \pm 29.3$ & 33 & 4 \\
\hline Height percentile & $58.7 \pm 27.6$ & 61.5 & $6 *$ \\
\hline $\mathrm{BMI}\left(\mathrm{kg} / \mathrm{m}^{2}\right)$ & $17.0 \pm 3.3$ & 16.2 & 16.2 \\
\hline BMI percentile & $28.3 \pm 27.2$ & 19 & 17,22 \\
\hline BMI Z-score & $-0.87 \pm 1.17$ & -0.91 & \\
\hline Amount of weight lost prior to assessment (kg) & $10.4 \pm 4.9$ & 11 & 13 \\
\hline Fat mass (\%) & $19.5 \pm 4.0$ & 20.5 & 11.4* \\
\hline Lean mass (\%) & $80.5 \pm 4.1$ & 79.7 & $73.5 *$ \\
\hline Water weight (\%) & $58.9 \pm 3.0$ & 58.3 & 59.6 \\
\hline
\end{tabular}

Table 1. Data about onset and first visit in children with debut of eating disorders.

AN: anorexia nervosa, BN: bulimia nervosa, BMI: body mass index, ED: eating disorder

* Mode could not be stated. Minimum displayed. 
Blood analysis was performed in most of the patients, showing a normal blood cell count. $47 \%$ had some alterations in biochemical parameters; the most frequent were hypercholesterolemia $(>200 \mathrm{mg} / \mathrm{dl})$ in $62.5 \%$ of the patients and hypoglycemia $(<55 \mathrm{mg} / \mathrm{dl})$ in $50 \%$ of them. 58\% had altered hormone levels, especially gonadotropin and sex hormones (lower estrogen levels in girls who had reached menarche previously).

Certain physical stereotypes and the idealization of thinness, and generalized body dissatisfaction encou- raged the onset of the disorder. $100 \%$ of them presented restriction of food intake, $90 \%$ expressed fear of gaining weight and more than $80 \%$ had unconsciousness of the disease, psychosocial changes, and even menstrual disorders such as amenorrhea in girls. Similarly, $75 \%$ presented a distorted body perception and acknowledged calorie-counting their intake. For those patients who achieved recovery at the time of the study $(n=15)$, the average follow-up time for hospital visits was 17 months. The evolution of the BMI of 12 patients is described in figure 1.

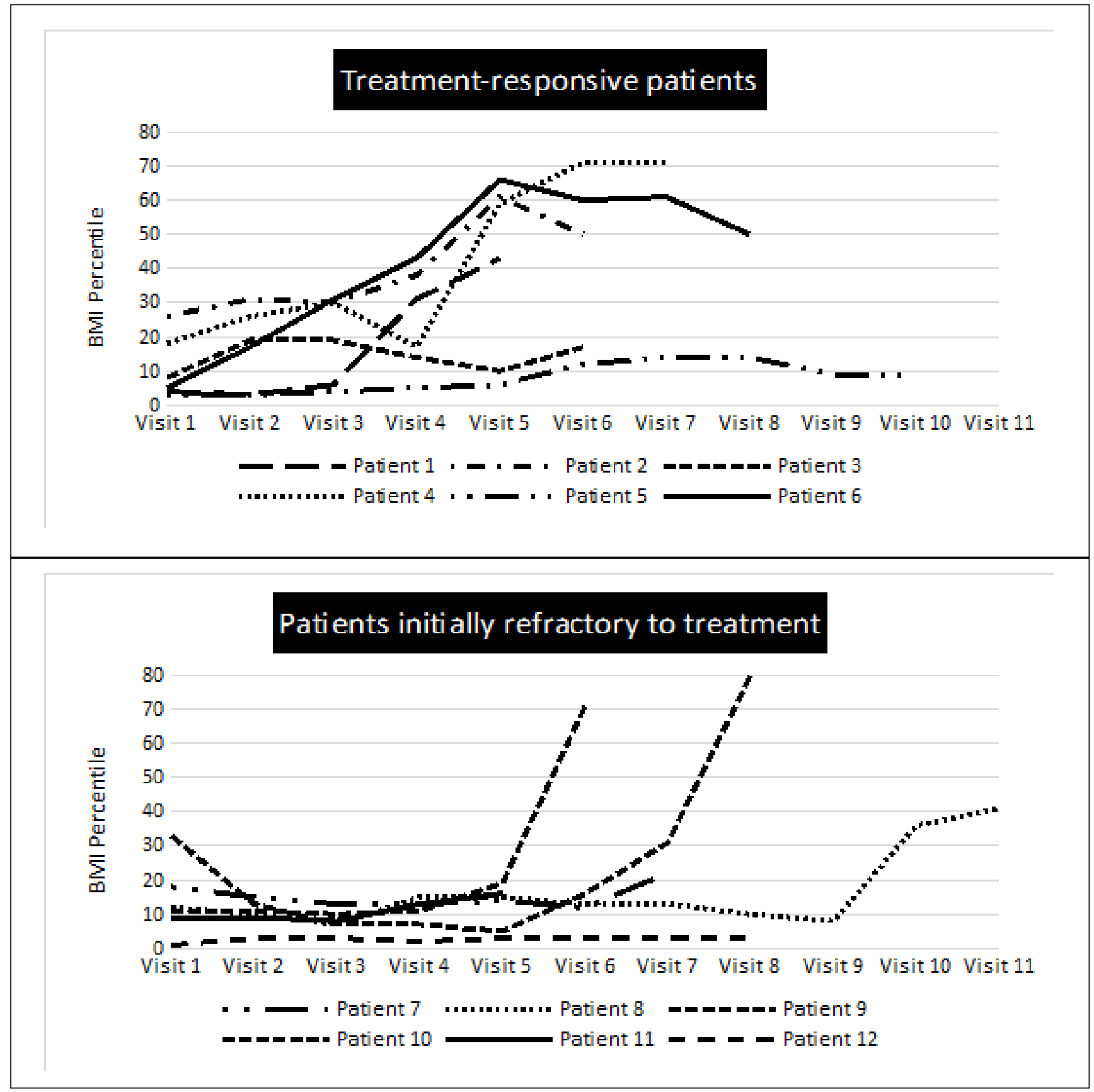

Figure 1. BMI evolution of treatment responders (A) and initial non-responders (B) during the first visit.

Figure 1.A: Initial responders were those who, from the first consultation, begin to increase their BMI and improve their physical condition. Figure 1.B: Non-responders or initially refractory to treatment were those who at the beginning of the visits maintain or even worse their anthropometric and metabolic status. 
Psychiatric comorbidities were also investigated and detected; in 70-75\%, depression and anxiety coincided, finding an identifiable trigger in $40 \%$ of patients with these disorders. Behavioral alterations and obsessive-compulsive disorder appeared in 10\%, family history of psychiatric illness in $20 \%$, and bullying and traumatic events in $10-25 \%$ of the children.

Concerning treatment, $100 \%$ of the patients needed personalized meal plans designed by a multidisciplinary group of professionals. In addition, $60 \%$ required nutritional supplements: $25 \%$ used micronutrient supplements, $20 \%$ hypercaloric beverages, and $15 \%$ used both. $65 \%$ of patients were prescribed for one or more types of psychoactive drugs, being antidepressants and anxiolytics the most common. One-third of the patients required hospitalization in, at least, one occasion during their treatment, but only one patient received nasogastric tube feeding and another two children required serum or glucose intravenous therapy.

\section{DISCUSSION}

The children in the present study have a particular profile with important differences, mainly regarding diagnosis, treatment objectives, approach and evolution, respect to reported in adults with ED.

The female-male sex ratio obtained is consistent with the bibliographic finding that these disorders mainly affect girls. Women have historically represented $90 \%$ of EDs and men only $10 \%$, but studies in recent years show that this figure might already reach around 25\% (11-13). These new findings are reflected in the latest updates to the DSM-V, which have accepted less sex-specific criteria, thus eliminating amenorrhea as a diagnostic criterion for AN $(8,14)$. It should also be highlighted the fact that younger patients diagnosed with ED, especially ARFID(15) and in our study, childhood-onset anorexia, are more likely to be male (15) than older patients: the ratio in adults is estimated to be $10: 1$ at $15: 1$, while in the pediatric and adolescent population it ranges from 6 to 1(16-18).

The mean age of onset of ED obtained through our data analysis was 11.3 years, which contrasts with other studies also carried out in children and adolescents, which states this age between 14 and 18 years $(12,19)$. This reported average can be conditioned by the lack of studies exclusively focus to pediatric age. So, these conditions can contribute to increase the age of debut. Notwithstanding, in recent studies have been observed a trend in the coming decades to decrease the age of onset with more debuts in pediatric stages $(15,20,21)$. On the other hand, the onset of $\mathrm{BN}$ is usually later, rarely being diagnosed in children under 14 years $(15,22)$. According to the present study, the evolution time range before the first consultation is 6.6 months, without differences by sex. In other studies, concerning EDs in children, this time is shown to be at least 2 years (8), maybe by different access to the health system.

Almost two-thirds of the patients were diagnosed with $\mathrm{AN}$, being consistent with binge/purge behaviors in studies with younger ED patients (6). Diagnosis may present more difficulty in this age spectrum due to the higher prevalence of atypical or incomplete forms (13) and may not be accompanied by physical deterioration at first but of interrupted or selective eating behaviors and character changes, as occurred in $80 \%$ of our patients.

One out of every four patients with AN developed a $\mathrm{BN}$ component throughout the disease, and in clinical practice it is noteworthy that this movement occurs in a higher percentage of males $(5,16)$. 36\% of patients with severe restrictive disorders previously had a high and premorbid BMI. This suggests that obesity and overweight may be risk factors for subsequent ED $(23,24)$ with an increased risk of late diagnosis $(10$ months later in our study) and the development of complications with a worse prognosis $(6,25,26)$.

The initial nutritional evaluation is the basic pillar of the physical examination. However, anthropometric data per se do not provide an accurate diagnosis as they may be normal in a patient with these diseases (i.e if the child showed obesity before) (27). In fact, the bioimpedanciometry offered data within the normal range in most of patients. It must be kept in mind that ED can present as a failure in weight gain rather than a loss of weight, so it can be misleading to evaluate patients only for their BMI (13). The BMI percentile was useful to classify the degree of severity, with $57.2 \%$ of our sample being in an extreme percentile $<15 \%$. The average weight loss before the first evaluation was $10 \mathrm{~kg}$, with less involvement of the height percentile, which corroborates that the weight percentile is affected earlier and to a greater extent, making early evaluation necessary compared with previous data as well as with future comparisons to evaluate the evolution $(12,28)$.

Complications can occur in children with ED even at non-alarmingly low weights, with chronicity markers being important $(2,8,19)$. At the first visit, most of the data was normal except for hormone levels and some biochemical markers, affected in approximately half of the patients. The most common alterations were hypercholesterolemia, reflecting the decrease in the elimination of bile acids in starvation conditions or by a greater reabsorption of endogenous cholesterol $(8,29)$, and hypoglycemia due to restricted intake. In patients with altered hormonal levels, low levels of gonadotropin and sex hormones, testosterone in men, and estrogens in women were found, due to hypothalamic suppression $(3,30,31)$. In fact, in $20 \%$ of the patients, amenorrhea preceded weight loss. Hypoestrogenic status is a risk factor for the development of osteopenia, osteoporosis, and pathological fractures, 
the main therapy being weight gain $(12,19)$. In this sample of children, no alterations were found in the count of blood or electrolytic cells, described above all in patients with purgative behaviors $(3,5,19)$. Clinical symptoms such as lanugo, dry and scaly skin, brittle hair and nails, bradycardia and hypotension and delayed pubertal development of secondary sexual characteristics were also observed in these patients $(12,21,31)$.

A family history of psychiatric illness was found in more than half of the patients, consistently to other studies $(8,16,17)$. Those with a family history of $\mathrm{AN}$ are 11.4 times more risk, while in $\mathrm{BN}$ they are 3.7 times (18). It seems that there is a positive relationship between excessive control, the application of strict dietary rules, and the individualization of food with the appearance of $\operatorname{ED}(4)$ with an influence of the genetic load (heritability of AN around 48-74\%) that condition the beginning before puberty or during adolescence $(11,14)$. Other risk factors found in the sample and reported, are the medium-high socio-economic level, insecure personality with low self-esteem, dependency, obsessive-compulsive tendencies, and identity problems (19). It is also worth noting the effects of cultural aspects related to the search for perfection and an ideal of beauty-focused on thinness, as well as the membership in certain groups where the key to success is related to weight control: social, modeling or sport clubs $(4,32)$.

Results of psychiatric comorbidity in our study are in harmony with the pre-existing findings $(11,18)$. The prevalence of, at least one comorbidity varies between $40-90 \%$ (8). Depression is a common comorbid diagnosis with rates of up to $63 \%(8,21)(70 \%$ in our sample) and between $25-75 \%$ of adult patients with ED have anxiety disorders $(13,21)$, affecting $75 \%$ of the children in the study. Obsessive-compulsive disorder appeared in $10 \%$ of our patients and has been described especially associated with AN (18). Severe life stress, as well as traumatic events in childhood, have been implicated in the development of ED (9); in fact, they were detected in $70 \%$ of children. It has been reported that people who have experienced some form of child abuse are three times more likely to develop an ED than the general population. Both emotional dysregulation and abuse are related $(32,33)$. However, those who had a traumatic event as an identifiable trigger (almost half of the patients in our sample) were more likely to recover (20).

Treatment was multidisciplinary (21), being the cornerstone of it nutritional recovery. A fundamental pillar is the individual psychotherapy programs (cognitive behavioral therapy) and therapy that actively involves the family (family-based treatment, FBT) finding the latter more effective. A systematic review from 2015 concluded that there is clear and growing evidence supporting the efficacy of FBTs in children and adolescents with AN and other restrictive disorders $(6,17,34)$. A large part of the patients with de- pression received drugs as a complement to the main treatment, resulting in a significant decrease in binge eating and purging. However, there is no solid evidence to support pharmacological treatment $(16,19)$. From 10 to $15 \%$ of the patients in our sample with a comorbid psychiatric disorder did not receive such treatment and yet did not perform worse; paradoxically, there is no evidence that pharmacological treatment has statistical significance in weight gain (34) or the reduction of EDs symptoms in people receiving multifaceted treatment, yet a meta-analysis concluded that depressive symptoms improved at the cost of increased anxiety $(5,8,18,21)$.

In our study, $58 \%$ of the children received oral nutritional supplementation (enteral hypercaloric and/or hyper-proteic formulas, vitamins...). Literature supports the use of these formulas and supplements, given they obtain a greater weight gain with the additional advantage of using small volumes, therefore avoiding the early appearance of satiety. Also, the fact that these supplements are considered as a "treatment" by the patient has been observed to reduce anxiety levels towards getting nutrients. However, as soon as nutritional status and reasonable intake allow, they should be replaced by food progressively (19). Patients with AN experience more serious complications than patients with $\mathrm{BN}$, with hospitalization being rare in the latter case $(3,5)$. Although our sample is formed of children with severe disease, only $35 \%$ required hospital admission at some point in their treatment, the proportion in adults being much higher (8).

There is no consensus on a precise definition of recovery. Most agree that it includes normalizing eating patterns, improving psychosocial, interpersonal, and occupational functioning, and in children and adolescents, restoring normal growth and pubertal patterns, and reversing most damage to the organs. The main difference in treatment in children is the difficulty of setting a weight goal, as the goals change as they grow. Reaching the minimum weight to restart growth and physical development (15) or a BMI percentile (according to sex and age) between 13 and 30 is reported (19). In some studies, $50 \%$ of children (up to $70-80 \%$ in adolescents) recover completely, $25 \%$ improve, 10 $20 \%$ develop a chronic ED (19) and 5\% die from complications (8) (mainly suicide and associated medical complications, with a death rate from $\mathrm{AN}$ for 10-12 times greater than in general population) $(18,19,21)$. In this sample, a half of children responded to treatment with a very good evolution since the initial assessment, while the other half had a first period of non-response to treatment, maintaining the changes and even worsening during the first 1-5 visits, but after that, there was a great improvement and a good evolution. Although there are still some follow-up patients, in those who achieved recovery, the average follow-up time varied from 2 to 42 months, compared to the duration of the disease in adults, which often exceeds 10 years, indicating a better prognosis and shorter duration of illness in children $(3,35)$. The 
main limitation in the present study is the difficulty to get a pediatric big sample with a large evolution and also that these patients were higher complex because they were selected from an specialized Hospital Unit.

In conclusion, there is a trend towards a decrease in the age of onset, an overall better health condition at first intervention, and a shorter duration of the disease than in adults. So, best prognosis in children could be explained by earlier diagnosis and intervention and closer follow-up of the multidisciplinary team, together with early mediation of parents. Greater dependence on their caregivers, increasing adherence to treatment and greater plasticity in the response to psychological therapies could also contribute to a better outcome in this age range. Overall, this type of studies can derive in specific proposals for improvement in the EDs care process, to design future multicenter projects to get a most representative and accurate profile of pediatric patients suffering from these diseases.

\section{BIBLIOGRAPHIC REFERENCES}

1. American Psychiatric Association: Diagnostic and statistical manual of mental disorders, $5^{\mathrm{a}}$ ed. Arlington: American Psychiatric Association; 2013:329-54

2. Unidad Técnica de Codificación CIE-10-ES Ministerio de Sanidad, Servicios Sociales e Igualdad $2^{\circ}$ edición 2016.

3. Rosen DS, American Academy of Pediatrics Committee on Adolescence. Identification and management of eating disorders in children and adolescents. Pediatrics. 2010;126(6):1240-53. DOI: 10.1542/peds.2010-2821

4. Erriu M, Cimino S, Cerniglia L. The Role of Family Relationships in Eating Disorders in Adolescents: A Narrative Review. Behav Sci (Basel). 2020;10(4):71. DOI: 10.3390/ bs 10040071

5. National institute for health and care excellence (NICE). Eating Disorders: recogniton and treatment (Nice Guideline NG69). 2017.

6. Campbell K, Peebles R. Eating disorders in children and adolescents: state of the art review. Pediatrics. 2014;134(3):582-92. 10.1542/peds.2014-0194

7. Fichter MM, Quadflieg N. Mortality in eating disorders results of a large prospective clinical longitudinal study. Int J Eat Disord. 2016;49(4):391-401. DOI: 10.1002/ eat. 22501

8. Hebebrand J, Herpertz Dahlmann B, editores. Trastornos de la conducta alimentaria y obesidad en niños y adolescentes. $1^{\text {a }}$ ed. Barcelona: Elsevier España; 2020:1-184
9. Luque Budía A, Aguilar Iñigo MC, Barrera Becerra C, Fernández Oropesa $\mathrm{C}$, Hernández Hernández MJ, Leiva Cabral MJ, et al. Trastornos de la conducta alimentaria. Proceso asistencial integrado. $2^{a}$ ed. Sevilla: Junta de Andalucía. Consejería de Salud; 2018

10. Sobradillo B, Aguirre A, Aresti U, Bilbao A, Fernández Ramos $C$, Lizarraga $A$, et al. Curvas y tablas de crecimiento (estudios longitudinal y transversal). $1^{\text {a }}$ ed. Bilbao: Fundación Faustino Orbegozo Eizaguirre; 2004.

11. Mairs R, Nicholls D. Assessment and treatment of eating disorders in children and adolescents. Arch Dis Child. 2016;101(12): 1168-1175. DOI: 10.1136/archdischild-2015-309481

12. Weaver L, Liebman R. Assessment of anorexia nervosa in children and adolescents. Curr Psychiatry Rep. 2011;13(2):93-8. DOI: 10.1007/s11920-010-0174-y

13. Berksoy EA, Özyurt G, Anıl M, Üzüm Ö, Appak YÇ. Can pediatricians recognize eating disorders? A case study of early-onset anorexia nervosa in a male child. Nutr Hosp. 2018;35(2):499-502. DOI: 10.20960/nh.1744

14. Timko CA, De Filipp L, Dakanalis A. Sex Differences in Adolescent Anorexia and Bulimia Nervosa: Beyond the Signs and Symptoms. Curr Psychiatry Rep. 2019;21(1):1. DOI: 10.1007/s11920-019-0988-1

15. Bryant-Waugh R. Feeding and Eating Disorders in Children. Psychiatr Clin North Am. 2019;42(1):157-67. DOI: 10.1016/j.psc.2018.10.005

16. Treasure J, Claudino AM, Zucker N. Eating disorders. Lancet. 2010;375(9714):583-93. DOI: 10.1016/S0140-6736(09)61748-7

17. Treasure J, Zipfel S, Micali N, Wade T, Stice E, Claudino $A$, et al. Anorexia nervosa. Nat Rev Dis Primers. 2015;1:15074. DOI: 10.1038/nrdp.2015.74

18. Kelly NR, Shank LM, Bakalar JL, TanofskyKraff M. Pediatric feeding and eating disorders: current state of diagnosis and treatment. Curr Psychiatry Rep. 2014;16(5):446. DOI: 10.1007/s11920-014-0446-z

19. Gómez Candela C, Palma Milla S, Miján de la Torre A, Rodríguez Ortega P, Matía Martín P, Loria Kohen V, et al. Consenso sobre la evaluación y el tratamiento nutricional de los trastornos de la conducta alimentaria: anorexia nerviosa. Nutr Hosp. 2018;35(1):11-48. DOI: 10.20960/nh.1562

20. Steinhausen HC, Jensen CM. Time trends in lifetime incidence rates of first-time diagnosed anorexia nervosa and bulimia nervosa across 16 years in a Danish nationwide psychiatric registry study. Int J Eat Disord. 2015;48(7):845-50. DOI: 10.1002/eat.22402

21. Herpertz-Dahlmann B, Dahmen B. Children in Need-Diagnostics, Epidemiology, Treatment and Outcome of EarIy Onset Anorexia Nervosa. Nutrients. 2019;11(8):1932. DOI: 10.3390/nu11081932 
22. Frank GKW, Shott ME, DeGuzman MC. The Neurobiology of Eating Disorders. Child Adolesc Psychiatr Clin N Am. 2019;28(4):629-640. DOI: 10.1016/j.chc.2019.05.007

23. Wiklund CA, Kuja-Halkola R, Thornton LM, Bälter $K$, Welch E, Bulik CM. Childhood body mass index and development of eating disorder traits across adolescence. Eur Eat Disord Rev. 2018;26(5):462-71. DOI: 10.1002/ erv. 2612

24. Cena H, Stanford FC, Ochner L, Fonte ML, Biino G, De Giuseppe $\mathrm{R}$, et al. Association of a history of childhood-onset obesity and dieting with eating disorders. Eat Disord. 2017;25(3):216-29. DOI: 10.1080/10640266.2017.12799 05

25. Swenne I. Influence of premorbid BMI on clinical characteristics at presentation of adolescent girls with eating disorders. BMC Psychiatry. 2016;16:81. DOI: 10.1186/ s12888-016-0788-7

26. Lebow J, Sim LA, Kransdorf LN. Prevalence of a history of overweight and obesity in adolescent with restrictive eating disorders. J Adolesc Health. 2015;56(1):19-24. DOI: 10.1016/j.jadohealth.2014.06.005

27. Kyle UG, Earthman CP, Pichard C, Coss-Bu JA. Body composition during growth in children: limitations and perspectives of bioelectrical impendance analysis. Eur J Clin Nutr. 2015;69(12):1298-305. DOI: 10.1038/ ejcn.2015.86

28. Ayton A. The Importance of Restoring Body Fat Mass in the Treatment of Anorexia Nervosa: An Expert Commentary. J Popul Ther Clin Pharmacol. 2019;26(3):e9-e13. DOI: 10.15586/jptcp.v26i3.629

29. Pires SAP, Soares JC, Luz AMBD, Moleiro P. Outpatient analytic assessment of anorexia nervosa - the importance of venous blood gases. Rev Paul Pediatr. 2020;38:e2018358. DOI: 10.1590/1984-0462/2020/38/2018358

30. Baskaran C, Misra M, Klibanski A. Effects of Anorexia Nervosa on the Endocrine System. Pediatr Endocrinol Rev. 2017;14(3):302-311. DOI: 10.17458/per.vol14.2017. BMK.effectsanorexianervosa

31. Schorr M, Miller K.K. The endocrine manifestations of anorexia nervosa: mechanisms and management. Nat Rev Endocrinol. 2017;13(3):174-86. DOI: 10.1038/nrendo. 2016.175

32. Brustenghi F, Mezzetti FAF, Di Sarno C, Giulietti C, Moretti P, Tortorella A. Eating disorders: the role of childhood trauma and the emotion dysregulation. Psychiatr Danub. 2019;31(Suppl 3):509-11.

33. Caslini M, Bartoli F, Crocamo C, Dakanalis A, Clerici M, Carrà G. Disentangling the association between child abuse and eating disorders: a systematic review and meta-Analysis. Psychosom Med. 2016;78(1):79-90. DOI: 10.1097/PSY.0000000000000233
34. Davis LE, Attia E. Recent advances in therapies for eating disorders. F1000Res. 2019;8:1693. DOI: 10.12688/ f1000research.19847.1

35. Gumz A, Uhlenbusch N, Weigel A, Wegscheider K, Romer G, Löwe B. Decreasing the duration of untreated illness for individuals with anorexia nervosa: study protocol of the evaluation of a systemic public health intervention at community level. BMC Psychiatry. 2014;14:300. DOI: 10.1186/ s12888-014-0300-1

\section{CONFLICTS OF INTEREST}

The authors of this article declare that they have no conflict of interest with respect to what is stated in this work.

\section{Si desea citar nuestro artículo:}

Ramírez Sánchez F, Jaimez Pérez S, Gil Campos M, Flores Rojas $\mathrm{K}$. The experience in pediatric patients with eating disorder for 10 years. Actual Med. 2020;811(105):182-189. DOI: 10.15568/am.2020.811.or05 